\title{
Entrevista a Julie Thompson Klein
}

por Maria Clara Paulino

A entrevista ocorreu em diferentes momentos entre 3 e 8 de agosto de 2017.

A Julie Thompson Klein se deve, em grande parte, a relevância que o processo interdisciplinar adquiriu ao longo das últimas décadas nos Estados Unidos, quer em contexto académico, quer entre comunidades científicas exteriores à academia. Galardoada com vários prémios pelo seu trabalho em prol da interdisciplinaridade, entre os quais o Kenneth Boulding Award for Outstanding Scholarship on Interdisciplinarity, o Yamamoorthy and Yeh Distinguished Transdisciplinary Achievement Award e o Joseph Katz Award for Distinguished Contributions to the Practice and Discourse of General and Liberal Education, Klein foi pioneira na definição de conceitos, processos e metodologias interdisciplinares. Presidente, durante largos anos, da Associação de Estudos Interdisciplinares (AIS) dos Estados Unidos e principal responsável pela revista publicada pela Associação, Issues in Integrative Studies, Klein lega-nos um largo corpus de obras hoje indispensáveis na formação de alunos e na construção de uma sólida metodologia de investigação interdisciplinar. Entre elas destacamos Interdisciplinarity: History, Theory, and Practice (1990), Crossing Boundaries: Knowledge, Disciplinarities, and Interdisciplinarities (1996), a monografia Mapping Interdisciplinary Studies (1999), Humanities, Culture, and Interdisciplinarity: The Changing American Academy(2005), Creating Interdisciplinary Campus Cultures(2010) e, mais recentemente, Interdisciplining Digital Humanities: 
Boundary Work in an Emerging Field (2015). Klein é responsável, com Robert Frodeman e Roberto Pacheco, pela edição do Oxford Handbook on Interdisciplinarity (2017). Após desempenhar funções como Senior Fellow da Association of American Colleges and Universities (AACU), foi nomeada, em 2011, Mellon Fellow e Visiting Professor in Digital Humanities da Universidade de Michigan. Klein colabora atualmente com várias universidades no desenvolvimento de programas interdisciplinares e é consultora para a investigação e educação interdisciplinares do Instituto Nacional de Saúde e da Academia Nacional de Ciência dos Estados Unidos. A nível internacional, Klein foi membro da Equipa de Investigação Integrativa da Academia da Finlândia, é consultora da Real Academia das Artes e Ciências da Holanda e representou os Estados Unidos em simpósios internacionais sobre a interdisciplinaridade, nomeadamente na Suécia, em Portugal e em França, com o apoio da OCDE e da UNESCO.

MCP: How do you define interdisciplinarity? Is it a method, a process, an "approach, " a point of view, or a full discipline with its own epistemology? Are you aware of other possible definitions?

JTK: The majority view is that interdisciplinarity is a process of integration, affirmed in two authoritative definitions. One, which a literature review indicates is the most widely cited definition, stems from the 2005 report on Facilitating Interdisciplinary Research (National Research Council)1: "Interdisciplinary research [IDR] is a mode of research by teams of individuals that integrates information, data, techniques, tools, perspectives, concepts, and/or theories from two or more disciplines or bodies of specialized knowledge to advance fundamental understanding or to solve problems whose solutions are beyond the scope of a single discipline or area of research practice" (2005:2). In addition, sources on interdisciplinary studies [IDS] in education also cite my own and William H. Newell's definition in the 1996 Handbook of the Undergraduate Curriculum²: "Approaches vary and disputes over terminology continue. Broadly speaking, though, interdisciplinary studies 
may be defined as a process of answering a question, solving a problem or addressing a topic that is too broad or complex to be dealt with adequately by a single discipline or profession" (1997: 3).

There is not a singular "method" because many are associated with achieving integration, including step-based models such as Allen F. Repko's, ${ }^{3}$ systems analysis, and others delineated in MacDonald et $a l^{4}$ and Bergmann et al's ${ }^{5}$ books on method. These two books have been crucial for a more informed approach to both inter- and transdisciplinarity, while arguing that the process entails not only integration but also collaboration. The term "approach" in definitions typically refers to approaches from disciplines. The notion of a "point of view" is associated more with a sense to attitude or an ethos, though it is not the majority definition. The notion of it being a "discipline" with its own epistemology is invalid at the global level when speaking about interdisciplinarity. There is a widespread belief that a successful interdisciplinary field may become a discipline in its own right, but this premise is often asserted as a general proposition that does not always hold up to evidence.

MCP: I'm interested in the idea that this is a premise that does not always hold up to evidence. Could you elaborate?

JTK: Well, it's based on a superficial simplistic assumption that there is one model for a discipline and one model for an interdisciplinary field. For example, molecular biology is a good example of an interdisciplinary field that became a discipline in its own right but social psychology did not, even though it has been influential. You could take also Women's Studies, which is a very successful field but is not necessarily an institutionalized discipline.

MCP: How does the interdisciplinary process contribute to cognition differently than the multidisciplinary process? Are there situations in which you see its contribution as more valuable? An interrelated question would be, are interdisciplinary approaches compatible with transdisciplinary ones? How would an interdisciplinary research project work with, say, gender studies, or post-colonial studies? 
JTK: I have delineated differences among inter-, multi-, and transdisciplinarity in The Oxford Handbook ${ }^{6}$. The question of cognition leads to both epistemological and social considerations. From an epistemological point of view, the concept of holism is the most frequent stance, though it is expressed in different ways by inter- and transdisciplinary theorists. That said, in all cases it contrasts with the singularity of a specialized viewpoint. In some examples of IDS within education, the value of a holistic mode of cognition is more than a contribution. It is a worldview for its own sake. More typically, though, and especially in IDR, it is considered a value-added dimension of thought and action, not for its own sake. The idea that it is essential, not just valued, has escalated with the increased imperative of problem-solving, accelerated by the rise of European-based transdisciplinary approaches that also involve stakeholders in society in the research process.

As for compatibility with transdisciplinary approaches, many studies acknowledge a role for both disciplinary and interdisciplinary approaches, though in the interest of transcending them through creation of a new conceptual or methodological framework. Hence, they are steps or contributions to the larger goal. As for how a project would work with gender or post-colonial studies, these areas typically involve critique around themes of importance to their respective fields and a more skeptical view of integration as the raison d'etre of IDS. In contrast, projects have a more instrumental imperative in problem-oriented fields such as criminology studies, policy science studies, and many science- and healthrelated areas.

MCP: When I hear you say that interdisciplinarity is essential and has escalated with the increased imperative of problem-solving, I wonder whether this imperative holds for the humanities and the arts as it does for other research areas. Is this imperative as clear in postcolonial and gender studies, for example, or could one say that to a large extent these are, in themselves, interdisciplinary?

JTK: That's a great question and it touches on so many points. First of all, there are some disciplines that have a synoptic scope already. If you're interested in cognition, the fact is that they already have breadth. There are disciplines that have always had a broad 
scope. History is a great example, as is Philosophy, which are broad in outlook to begin with. Other disciplines like art history, for example, have at times historically followed synthetic paradigms that are often talked about as interdisciplinary, whether accurately or not. Take the notion of period style, for example: periodization is an excellent example of what is often operating as an interdisciplinary synthesis. Although, as you well know, that has been criticized for being biased to certain perspectives, certain works in the canon, certain artists, certain cultures. Then along came a form of interdisciplinarity that I like to call critical interdisciplinarity. This is not the older synoptic breadth, neither it is the synthesis of a paradigm, such as periodization; rather, it is informed by new poststructuralism theories and even, in some cases, by critical race theory. So, just taking those three: the synoptic scope, the synthesis of periodization, and then the critical interdisciplinarity critique -- they have all been associated with interdisciplinarity at one point or another, but they differ. Somebody who is trying to understand how something fits within a historical period is not doing the same kind of work as somebody in post-colonial or gender studies who is, in short, drawing on methods and theories from more than one discipline while also having a critical imperative: the imperative of critique. All of those are different than the simple multidisciplinary throwing together of different perspectives, though they can be reduced to that.

MCP: Coming from the humanities, I must say I'm yet to find in the literature an indepth discussion about interdisciplinary approaches in the humanities and the fine arts. The debate seems to be much more open and clear in the so-called hard sciences.

JTK: And it's become more so. We have an excellent chapter in the newest edition of the Oxford Handbook of Interdisciplinarity on biological sciences, which just shows that the word discipline no longer works to describe it because it has become a much more interdisciplinary field. You just reminded me, since you are in art history, that there is a fourth thing we could talk about that is beautifully expressed by Mieke Bal as traveling concepts $^{7}$. I think travelling concepts is one of the most important ways of thinking about interdisciplinarity in the humanities and arts. What she does is that she refuses an eclectic 
multidisciplinary approach. Doing interdisciplinarity is not just surfing and zapping, as she likes to call it: it's about a very focused kind of work where you are trying to address a question or a problem or an object. For example, in her book she takes a piece of graffiti and analyzes it by constructing an interdisciplinary framework for understanding that is driven by the nature of the object. She asks a lot of questions about meaning, and these questions are very much humanities questions about meaning and significance. This is different than simply applying a critical theory, which is still legitimate; it's different than a broad synoptic scope, which can often be multi-disciplinary; and it's different than a paradigm such as periodization. I really like that book because she says there are all these different traveling concepts: the image, for example, which is so central to the humanities and the arts. When it travels around, an image picks up new meanings as it contacts with other contexts. Of course, for disciplinary purists this raises the question of whether or not the work is authentic, but her metaphor of travel is really genius.

MCP: Yes, it is very good. In fact, it's exactly how things are, isn't it? In practical terms, that's what happens.

JTK: And I think it is very helpful to have that example to make clear distinctions. In the Association for Interdisciplinary Studies you see people who are in general and liberal study programs, who want to cultivate a broad intelligence, a broad cultural understanding, but that is very different than what Bal is talking about. She is talking about a focused study of a problem to understand the meaning of an object. Now, all these approaches are legitimate, but they differ.

MCP: In my experience with teaching undergraduates how to apply interdisciplinary models, using your books and Allen Repko's, I found the process to be rigorous and to require a well-defined set of skills. I'd like to hear your thoughts on this.

JTK: There is not a singular interdisciplinary method. See, for example, Michael 0’Rourke's work on different conceptions of integration ${ }^{8}$. Moreover, adherence to a stepmodel of IDS has been criticized. Gunila Öberg's primer on environmental studies ${ }^{9}$ is an 
effective method with students, and numerous studies of educational programs fostering requisite skills for inter- and transdisciplinary research have expanded thinking in this area. The work of Maura Borrego ${ }^{10}$ and Shalini Misra ${ }^{11}$ are noteworthy for delineating related skills.

MCP: I did have difficulty with the step-based approach as detailed in Allen Repko's book. It seemed too rigid at times. The traveling concepts idea is more appealing, while retaining precision: one would have to be laser-beam focused on how one concept travels from one place to the other, what connotations it acquires, what shapes it shows itself in.

JTK: Yes, and I like your metaphor, that it's laser-like. Allen Repko is a friend of mine, and I respect the work he has done but I am much more pluralistic about this question of method. When Allen wrote that book ${ }^{12}--$ and he is now joined by Rick Szostak -- he wrote it for individual projects. It's a textbook, and it works in classes where there is the time to go through all of those steps. I never used it because I was teaching in classes where there was not the time to invest in that single method. I found that parts of it were very effective, like the way he breaks down a particular step, and other things were useful too. But we deliberately invited Michael O'Rourke, a philosopher, to write the chapter on methods of integration for the latest edition of the Oxford Handbook. He does a brilliant job of sorting out the differences. He talks about how some methods are top-down driven, such as Repko's ten-step model, requiring going through all the given steps. There are other stepmodels out there, which Michael discusses in the chapter, that are not top down driven, but rather bottom-up. We can look at Bal's approach, in which the important thing is what the problem requires people to do in the way of process rather than being loyal to a particular set of steps. Step models have been criticized especially in the transdisciplinary research network and sustainability studies, where there is a much greater appreciation of the fact that iteration is part of the process. It's not going from step one to step two to step three, but rethinking the prior steps. And that makes sense with Bal too, because what Bal is doing is creating a testing environment.

So, there are many models out there and in fact, there's a new four-phase model in 
the health sciences for transdisciplinary work. I always like to look at those to learn what I can from them, but as I have become more involved in the transdisciplinary sustainability network, I've come to appreciate that, particularly when research involves stakeholders in society, the process is always one of negotiation. It's negotiating knowledge. That's a different context than what Bal is doing in humanities and arts but it's still more processbased, without requiring linear steps. There is also a factor in the humanities that you and I can appreciate, which is the tension between qualitative empirical approaches and qualitative ones. I think we have a much clearer sense now that there are many factors, variations, and approaches, which doesn't mean we can't find value in each. It's a matter of what fits for the work at hand.

MCP: It's good to hear this. You know, often the objection to interdisciplinarity is that its borders are too undefined; yet, once it sinks in that it is a rigorous process, the objection is then that it is too focused, particularly for the humanities. That's been my experience.

JTK: I've been thinking about this a lot lately. I'm in a team science network and one of our colleagues in the network is a grant officer at the National Institute of Health. She said she had a scientist who refused to do anything with team science that was interdisciplinary in nature because he thought it would either be specialist or generalist. But that is a false dichotomy, a misunderstanding of what you and I are talking about, which is a form of hybrid-specialization. And in fact, a lot of work in the sciences does exactly that: it takes a particular specific arena, such as genomics, but the work that goes on in specific projects and programs has a focus on a set of problems at hand. There is a similarity here, although in a more empirical scientific-driven quantitative environment than what we do in humanities and art.

MCP: A question often raised is that of disciplinary identity, of how much disciplines have to "lose," or to give up, when they engage with other disciplines with the purpose of reaching an interdisciplinary solution. Is a discipline ever in danger of losing its identity?

JTK: This question raises both political and social considerations. The belief that 
disciplines lose is widely held, and framed as a sacrifice. However, studies of collaborative research, especially in the transdisciplinary and science of team science networks, have focused on the necessity of sacrificing strict adherence to disciplinary protocols to achieve an integrated result. As for disciplinary identity, loss is a concern. However, longitudinal studies of disciplines reveal that disciplines change over time and are increasingly pluralistic in nature, as well as increasingly interdisciplinary. This fact challenges the dichotomy of disciplinarity versus interdisciplinarity. To say someone is a biologist, for example, doesn't tell us much about which part of the expanse of practices s/he identifies with personally, while exposing the danger of claiming that biological sciences have a singular identity they lack and ignoring the impact of IDR on the nature of the disciplines. Examples appear in multiple chapters in the 2017 edition of The Oxford Handbook ${ }^{13}$, including entries on biology and humanities.

MCP: I'd like to end this conversation with a question about interdisciplinarity in academia. In the U.S., are Interdisciplinary Studies programs supported by career structures, promotion guidelines, or funded lines of research? And, are you aware of the situation outside the U.S.?

JTK: Ludwig Huber once referred to the United States as "the El Dorado of interdisciplinary studies." 14 Given the number and plurality of practices, that generalization remains valid. Brint et al.'s longitudinal study of interdisciplinary majors ${ }^{15}$ provides more recent concrete evidence. The questions about career structures and validity are addressed at length in the 2005 NRC [National Research Council] Report on Interdisciplinarity as well as the NRC 2014 Report on Convergence and the 2015 Report on Enhancing the Effectiveness of Team Science. Promotion and tenure ${ }^{16}$ are recognized as key impediments, though I have an article just published in Research Policy ${ }^{17}$ on changes being made to be more conducive to this kind of work in the P\&T [Promotion and Tenure] process. AIS [Association of Interdisciplinary Studies] also has guidelines for IDS on its website, the result of a task force on the topic of P\&T. There are numerous examples of IDS outside the US, usually in particular fields. I'd note, though, the new Ph.D. program on Interdisciplinarity at the 
University of Geneva. Outside the U.S. there is also greater momentum for transdisciplinarity at present, with a large literature that can be glimpsed on the td-net website: http://transdisciplinarity.ch/td-net/Aktuell.html.

MCP: We've come to the end of our conversation, Julie. Thank you so much for your time.

JTK: My pleasure, Clara. Looking forward to continuing this discussion some other time.

\section{NOTES}

1 National Academy of Sciences, National Academy of Engineering, and Institute of Medicine (2005). Facilitating Interdisciplinary Research. Washington, DC: The National Academies Press.

${ }^{2}$ Gaff, Jerry G, and James L. Ratcliff (1997). Handbook of the Undergraduate Curriculum: A Comprehensive Guide to Purposes, Structures, Practices, and Change. San Francisco: Jossey-Bass Publishers.

3 Allen F. Repko é co-autor de textos vários adoptados em programas interdisciplinares, em contexto académico, tais como Introduction to Interdisciplinary Studies, de 2014, e Interdisciplinary Research: Process and Theory, de 2016.

${ }^{4}$ McDonald, David e Gabriele Bammer (2009). Research Integration Using Dialogue Methods, Australia: ANU Press.

${ }^{5}$ Bergmann, Matthias et al (2013). Methods for Transdisciplinary Research. A Primer for Practice. Trad. R. Faust. University of Chicago Press.

${ }^{6}$ Frodeman, R., J. T. Klein e Pacheco, R., eds. (2017). The Oxford Handbook of Interdisciplinarity. Oxford University Press.

N. 37 - 12/ 2017 | 201-211 - ISSN 2183-2242 | http:/dx.doi.org/10.21747/21832242/litcomp37e1 
7 Bal, Mieke (2002). Travelling Concepts in the Humanities: A Rough Guide. Toronto: University of Toronto Press.

${ }^{8}$ O'Rourke, Michael et al. (2013). Enhancing Communication and Collaboration in Interdisciplinary Research. Sage Publications, Inc.

9 Öberg, Gunilla et al. (2011). "The Notion of Sewage as Waste - On Institutional Inertia and Infrastructure Change in Buenos Aires, Argentina and Vancouver, Canada", Ecology and Society, 19(2):19.

10 Borrego, Maura (2014). "Interdisciplinary Graduate Programs Worth the Challenge", Higher Ed as a Business, acessível em https://evolllution.com/opinions/audio-interdisciplinary-graduate-programs-worthchallenge/.

11 Stuhler, Elmar A. e Shalini Misra, eds. (2008). Across disciplinary boundaries towards a sustainable life: Psychodynamic reflection on human behavior, Rainer Hampp Verlag.

${ }^{12}$ Repko, Allen F. e Rick Szostak (2016). Interdisciplinary Research. Process and Theory, Sage Publications. ${ }^{13}$ Idem.

${ }^{14}$ Huber, L. (1992). "Editorial", European Journal of Education 27(3), 193-199 e Huber, L. (1989). "Teaching and learning - students and university teachers", European Journal of Education 24(3), 271-288.

15 Brint, Stephen G. et al. (2009). "Expanding the Social Frame of Knowledge: Interdisciplinary, DegreeGranting Fields in American Colleges and Universities, 1975-2000", The Review of Higher Education, 32(2),155-183. The Johns Hopkins University Press.

${ }^{16}$ Progressão na carreira académica e agregação.

${ }^{17}$ Klein, Julie Thompson e Holly J. Falk-Krzesinski (2017), "Interdisciplinary and collaborative work: Framing promotion and tenure practices and policies", Research Policy, 46(6), 1055-1061.

N. 37 - 12/ 2017 | 201-211 - ISSN 2183-2242 | http:/dx.doi.org/10.21747/21832242/litcomp37e1 